\title{
Feldspat cevheri karakterizasyonunda flotasyon yönteminin önemi
}

\author{
Gül AKAR ŞEN ${ }^{1 *}$, Hatice YILMAZ ${ }^{1}$ \\ ${ }^{l}$ Dokuz Eylül Üniversitesi Müh. Fak. Maden Müh. Böl., Tınaztepe kampüsü, İzmir. \\ Geliş Tarihi (Received Date): 22.04.2021 \\ Kabul Tarihi (Accepted Date): 03.12.2021
}

Öz

Bu çalışmada Aydın Çine bölgesinden alınan feldspat cevheri içerisindeki mineraller; minerolojik, kimyasal ve feldspat zenginleştirme yöntemlerinden olan flotasyon yöntemi kullanilarak karakterize edilmiştir.. Geleneksel yöntemler ile(XRD) cevherin ana mineralinin albit (Na feldspat) ve ikincil mineralinin kuvars olduğu kolaylikla belirlenmiştir. Ancak; kimyasal analizle belirlenen demir, titanyum, kalsiyum, magnezyum gibi elementlerin kaynağl olabilecek (muskovit, rutil, sfen, ilmenit, hematit, apatit vb olabilir) minerallerin cevher içerisindeki konsantrasyonlarının düşük olması nedeniyle net bir pik elde edilememiştir. Cevher içerisindeki oranları çok düşük olan ve doğrudan analiz yöntemlerinin yetersiz kaldiğl bu durumda eser mineralleri belirleyebilmek amacıla cevhere flotasyon işlemi uygulanmıştır. Böylece feldspat cevheri flotasyon yöntemi ile zenginleştirilirken, mika ve ağır mineral ürünlerindeki eser minerallerin pikleri XRD yöntemi ile tespit edilebilmiştir.

Anahtar kelimeler: Feldspat, karakterizasyon, flotasyon, mika ve ağır mineral, XRD

\section{Importance of flotation method in feldspar ore characterization}

\begin{abstract}
In this study, minerals in feldspar are intented to be characterized by the use of the flotation method which is one of the feldspar enrichment methods and minerological, chemical analysis. Feldspar samples are taken from Aydın Çine region. With traditional methods (XRD), it was easily determined that the main mineral of samples is albite (Na feldspar) and the secondary mineral is quartz. But; The minerals (muscovite, chlorite, rutile, sphene, ilmenite, hematite, apatite, etc.) that could be the source of elements such as iron, titanium, calcium, magnesium, could not be determined clearly due to the low
\end{abstract}

*Gül AKAR ŞEN, gul.akar@deu.edu.tr, http://orcid.org/0000-0002-9277-3961

Hatice YILMAZ, hatice.yilmaz@ deu.edu.tr, http://orcid.org/https:/0000-0001-9481-8126 
concentrations in the ore. Flotation process was applied to the ore in order to determine the trace minerals in this situation where the ratio in the ore is very low and direct analysis methods are insufficient. Thus, while feldspar ore was enriched by flotation method, peaks of trace minerals in mica and heavy mineral products could be determined by XRD method.

Keywords:Feldspar, characterization, flotation, mica and heavy minerals, XRD.

\section{Giriş}

Feldspatlar yerkabuğunun \%60-65'ini oluşturan sodyum, potasyum, kalsiyum, lityum ve bazen de baryum ve sezyum ve bu elementin izomorf yer değiştirmesi ile oluşmuş susuz alümina silikatlardır $[1,2]$. Seramik ve camın ana hammaddesi olan ve ülkemizde yaygın olarak bulunan feldspatlar çoğu zaman demirli ve titanyumlu safsızlık mineralleri (rutil, sfen, mika, kil, vb.) içerirler .Endüstriyel olarak kullanılan feldspatlarda en az \%9,5 $\mathrm{Na}_{2} \mathrm{O}$ ve \%8-9 $\mathrm{K}_{2} \mathrm{O}$ içeriği istenirken, \%0,15-0,3 $\mathrm{TiO}_{2}$ ve $\% 0,10 \mathrm{Fe}_{2} \mathrm{O}_{3}$ içeriği kabul edilebilir en üst sınırlardır. Türkiye feldspatları oldukça iyi kalitede olmalarına rağmen endüstriyel olarak istenilen bu standartlara sahip olmadıklarından mutlaka zenginleştirilmeleri gerekmektedir. Feldspatların zenginleştirilmesinde en çok uygulanan yöntem, flotasyon olup, feldspatların yaklaşık \%70'i bu yöntemle zenginleştirilmektedir [3-5]. Ancak uygulanacak flotasyon işlem aşamaları feldspatlar içerisindeki safsızlıklara bağlı olarak değişmektedir.

Feldspatın en çok tüketildiği seramik ve cam sektörlerindeki en önemli ortak nokta demir ve titanyum içeriğidir. Züccaciye camında demirin 400 ppm'in altında olmas1 gerekmektedir. Seramik endüstrisinde ise, titanyum oksit içeriği de demir kadar belirleyici olup, demir ve titanyum içeriği düştükçe pişme rengi beyazlaşmakta ve feldspatın fiyatını arttırıcı bir unsur olmaktadır. Seramik sanayi hammaddesi için Na ve $\mathrm{K}$ feldspatların içindeki safsılılıkların giderilmesi, $\mathrm{K}_{2} \mathrm{O}$ ve $\mathrm{Na}_{2} \mathrm{O}$ içeriklerinin belirli sınırlarda ve ürünlerin beyaz pişme renginde olması gerekmektedir [6,7]. Cam üretiminde kullanılacak feldspat üretimi için, kuru manyetik ayırma işlemi ile mika (biyotit, muskovit) ve demir oksit mineralleri ayrilabilmekte ancak,seramik endüstrisinin talep ettiği yüksek kaliteli Na-feldspat konsantresi $\left(\mathrm{TiO}_{2}<\% 0,10\right)$ üretimiiçin, rutil ve sfenin manyetik duyarlıklarının çok düşük olması nedeniyle ancak flotasyonla uzaklaştırılmaları mümkün olmaktadır [8-10].

Feldspat flotasyonu genel olarak üç aşamadan oluşmaktadır. Şlam atma işlemini takiben birincisi mika flotasyonu, ikincisi ağır mineral flotasyonu ve üçüncüsü de feldspat flotasyonudur. Cevher içerisinde mika mineralleri yok denecek kadar azsa ve kabul edilebilir sınırlarda ise mika flotasyonu atlanabilir. Yine cevher içerisindeki kuvars miktarı çok düşük ise flotasyonun son aşaması yapılmadan feldspat ve kuvars konsantresi birlikte alınabilir. Sonuç olarak uygulanacak flotasyon işlem aşamaları cevherin içerisindeki safsızlık minerallerine ve bunların oranlarına bağlı olarak belirlenmektedir. Çoğu zaman safsızlık minerallerinin oranları çok düşük olup klasik analiz cihazlarının belirleyebileceği dedeksiyon limitlerinin çok altında olabilir. Bu durumda söz konusu minerallerin tespiti için cevherin konsantre edilerek cihazların dedeksiyon limitleri sınırlarına getirilmesi gerekir [11]. Dolayısıyla feldspatları zenginleştirmek için yaygın olarak kullanılan flotasyon yöntemi, safsılılı minerallerinin 
örnek içerisindeki oranlarını arttırmak ve net olarak tespitlerini sağlamak amacıyla kullanılabilir.

$\mathrm{Bu}$ çalışmada, cevher içerisindeki ana mineral albit ( $\mathrm{Na}$ feldspat) ve ikincil mineral kuvars kolaylıkla tespit edilirken, kimyasal analizle belirlenen demir, titanyum, kalsiyum, magnezyum gibi elementlerin kaynağı olabilecek minerallerin cevher içerisindeki varlığı tespit edilememiştir. Ham cevherde XRD analizi sonucunda belirlenemeyen olas1 minerallerin (muskovit, klorit, rutil, sfen, ilmenit, hematit, apatit $\mathrm{vb}$ olabilir) tespiti için cevher iki kademeli flotasyon yöntemi ile zenginleştirme işlemine tabi tutulmuştur. Elde edilen mika konsantresi ve ağır mineral konsantresinin XRD yöntemi kullanılarak mineralojik karakterizasyonu yapılmıştır.

\section{Malzeme ve Yöntem}

\subsection{Malzeme}

Bu çalışmada; seramik ve cam sektörünün temel hammaddesi olan ve ülkemizde de yaygın olarak bulunan Aydın Çine bölgesine ait feldspat cevheri ile çalışılmıştır.

\subsection{Numune Hazırlama}

Yaklaşık $100 \mathrm{~kg}-12 \mathrm{~cm}$ tüvenan cevher olarak alınan numuneden mikroskobik incelemeler yapmak üzere parça numuneler seçilmiş ve bu parçalardan ince kesit numuneleri hazırlanmıştır. Kalan malzeme çeneli kırıcı çıkış açıklığ 5 mm olacak şekilde açılmış ve kapalı devre olarak kırılmıştır. Kırılan malzemenin tamamı Riffle numune bölücü kullanılarak yaklaşık 25 kg'lık dört kısma ayrılmıştır. Flotasyon deneyleri için malzemeden $25 \mathrm{~kg}$ 'lık bir kısım önce korumalı kırma işlemi ile $-2 \mathrm{~mm}$ altına getirilmiş ardından malzemenin \%80'i $-212 \mu \mathrm{m}$ altına geçecek şekilde seramik bilyalı değirmende ögütülmüştür. Öğütülen malzemenin tamamı 8 hazneli kavanozlu numune bölücü ile her biri yaklaşık $200 \mathrm{~g}$ olacak şekilde bölünmüş ve ağzı kilitli torba ile poşetlenerek saklanmıştır. Ayrıca, tungsten karbür değirmen ile $100 \mu$ m'nin altına öğütülerek kimyasal ve mineralojik analizler için malzeme hazırlanmıştır.

\subsection{Karakterizasyon çalışmaları}

İlk olarak tüvenan cevherden alınan parça örneklerden hazırlanan ince kesitlerin mineralojik ve petrografik incelemeleri Layka marka mikroskop ile yapılmıştır. Öğütme işleminden sonra numune hazırlama ve bölme işlemleri ile hazırlanan temsili feldspat numunesinden $0,850 \mathrm{~mm}, 0,500 \mathrm{~mm} 0,300 \mathrm{~mm}, 0,150 \mathrm{~mm}, 106 \mu \mathrm{m}, 75 \mu \mathrm{m}$ ve $53 \mu \mathrm{m}$ elek açıklığına sahip elekler kullanılarak elek analizi yapılmıştır. Elde edilen fraksiyonel numunelerin elek metal bilançolarını hazırlamak üzere kimyasal analizleri lityum tetraborat eritiş yöntemi uygulanarak yapılmış ve çözeltilerdeki element içerikleri Perkin Elmer Atomik Absorpsiyon Spektrofotometresi (AAS) kullanilarak belirlenmiştir. Malzemenin flotasyonundan sonra elde edilen ürünler ve besleme malının binoküler mikroskop incelemeleri Nikon marka SMZ 1500 mikroskop ile yapılmıştır. Yine hem besleme malının hemde flotasyon ürünlerinin mineralojik bileşimleri $30 \mathrm{kV} / 15 \mathrm{~mA}$ 'da $\mathrm{CuK} \alpha \mathrm{X}$ 1şın kaynağı ve grafit monokromatör kullanılarak Rigaku MiniflexII X Işını Kırınım cihazı (XRD) ile 2\%/dak tarama hızında çekilen XRD grafikleri yardımıyla belirlenmiştir. Diferansiyel termal analiz ve termogravimetrik analizleri (DTA/TGA) Shimatzu DTG $60 \mathrm{H}$ marka cihaz ile $10^{\circ} \mathrm{C} /$ dak. tarama hizinda 20-1000 ${ }^{\circ} \mathrm{C}$ sıcaklık aralığında yapılmıştır. Fourier Transmision Infrared analizleri 
Perkin Elmer Spectrum One ATR-FTIRcihazı ile $650-4000 \mathrm{~cm}^{-1}$ aralığında alınan FTIR grafiği üzerinden yapılmıştır.

\subsection{Flotasyon}

$\mathrm{Bu}$ çalışmada, besleme malının kimyasal analiz ile belirlenen ancak düşük konsantrasyonları nedeniyle XRD ile dedekte edilemeyen fakat feldspat cevherinin kullanım alanları açısından sorun yaratan elementlerin kaynağı olan eser mineralleri belirleyebilmek amacıyla feldspat cevherine iki kademeli klasik bir feldspat flotasyonu işlemi uygulanmıştır. Minerallerin fiziko-kimyasal özellik farklarından yararlanarak uygulanan bir zenginleştirme metodu olan flotasyon, bu çalışmada cevher içerisinde oranları çok düşük olduğu için belirlenemeyen minerallerin analiz cihazlarının dedekte edilebileceği oranlara konsantre edilmesi amacıyla kullanılmıştır.

\section{Deneysel Çalışmalar}

\subsection{Elek Analizi}

Öğütülmüş malzemenin elek analizi, yaklaşık 500 gram numune ile 0,850 mm, 0,500 $\mathrm{mm}, 0,300 \mathrm{~mm}, 0,150 \mathrm{~mm}, 106 \mu \mathrm{m}, 75 \mu \mathrm{m}$ ve $53 \mu \mathrm{m}$ elek açıklığına sahip elekler kullanılarak, Retsch marka otomatik elek makinesi ile yaş olarak yapılmış ve elek altı elek üstü dağılım grafikleri çizilmiştir (Şekil 1). Şekil 1'den de görüldüğü üzere malzemenin \%80'ini $180 \mu \mathrm{m}$ altındadır.

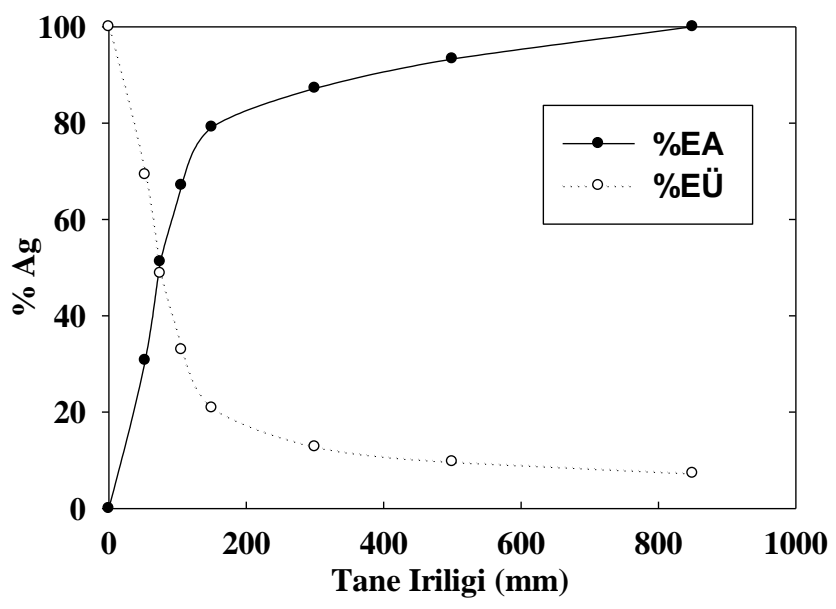

Şekil 1. Feldspat numunesi elek analiz sonucu

\subsection{Kimyasal Analiz}

Besleme malı analizi için, lityum tetraborat eritiş metodu ile hazırlanan flaksların \%10'luk $\mathrm{HCl}$ ile çözülmesi sonucu elde edilen çözeltilerden Perkin Elmer Atomik Absorpsiyon Spektrofotometresi (AAS) kullanılarak majör element derişimleri belirlenmiş, sonuçlar oksit bazında Tablo 1'de verilmiştir. 
Tablo 1. Malzemenin kimyasal analiz sonucu

\begin{tabular}{|c|c|}
\hline Element & \% \\
\hline $\mathrm{Al}_{2} \mathrm{O}_{3}$ & 19,20 \\
\hline $\mathrm{SiO}_{2}$ & 67,66 \\
\hline $\mathrm{Fe}_{2} \mathrm{O}_{3}$ & 0,12 \\
\hline $\mathrm{CaO}$ & 0,64 \\
\hline $\mathrm{MgO}$ & 0,06 \\
\hline $\mathrm{Na}_{2} \mathrm{O}$ & 10,49 \\
\hline $\mathrm{K}_{2} \mathrm{O}$ & 0,19 \\
\hline $\mathrm{TiO}_{2}$ & 0,79 \\
\hline $\mathrm{P}_{2} \mathrm{O}_{5}$ & 0,27 \\
\hline $\mathrm{KK}$ & 0,55 \\
\hline
\end{tabular}

AAS de baz alınan element absorbans değerleri en az üç noktadan geçecek şekilde hazırlanan kalibrasyon eğrisi kullanılarak her bir numune en az üç kere okutulmuştur.

\subsection{Mineralojik Analiz}

Feldspat numunesinin mineralojik bileşimlerini belirlemek amacıyla XRD, binoküler mikroskop, ince kesit incelemeleri yapılmıştır.

\subsubsection{XRD Analizi}

$100 \mu \mathrm{m}$ altına öğütülen besleme malının XRD analizi sonucunda ana mineral olarak albit (Na Feldspat-Plajioklas) ikincil mineral olarak kuvars içerdiği tespit edilmiştir (Şekil 2). Ancak XRD ile belirlenen mineralojik bileşim, kimyasal analizle belirlenen $\mathrm{Ca}, \mathrm{K}, \mathrm{Fe}$ ve Ti'un (Tablo 1) kaynağı olan mineralleri tespit etmek için yeterli olamamıştır. $\mathrm{Bu}$ elementler muhtemelen feldspatlarda eser miktarlarda bulunan muskovit, hematit, apatit, rutil vb. minerallerden kaynaklanıyor olabilir.

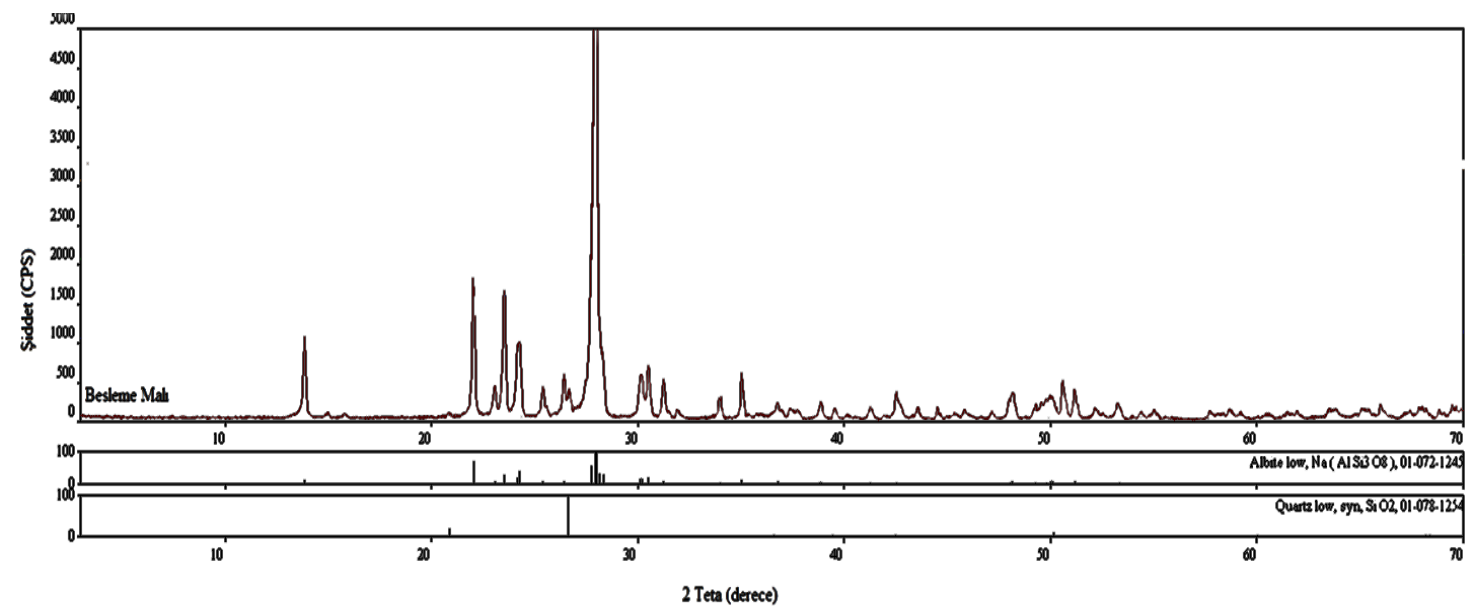

Şekil 2. Besleme malı XRD grafiği

$\mathrm{Bu}$ minerallerin varlığını net olarak belirlemek için farklı karakterizasyon teknikleri kullanılabilir. Ancak çoğu zaman düşük konsantrasyonları nedeniyle analiz cihazlarının dedeksiyon limitlerinin altında kalabilirler. 


\subsubsection{Binoküler mikroskop incelemesi}

Besleme malı feldspat cevherinin binoküler mikroskop incelemesi sonucunda XRD metodu ile belirlenen ana mineral Na-feldspat (albit) ve ikincil mineral kuvars varlı̆g makro ölçekte de tespit edilmiștir (Şekil 3). Albit ve kuvars yanında karakteristik bal sarısı rengi ile rutil ve renk verici diğer mineral taneleri feldspat ve kuvarsla birlikte veya serbest taneler halinde görülmüştür.

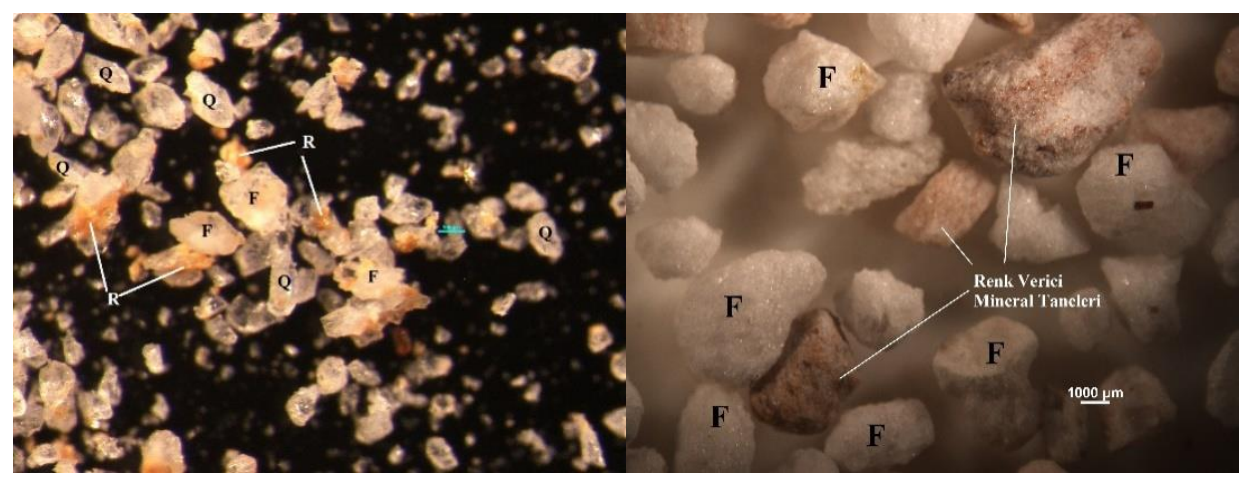

Şekil 3. Besleme malı binoküler mikroskop görüntüleri

(R: Rutil, F: Na-Feldspat (albit), Q: Kuvars)

\subsubsection{Ince kesit incelemesi}

Feldspat besleme malı örneğinden hazırlanan ince kesitlerin incelenmesi sonucunda malzemede bol miktarda plajioklas (albit: Na-feldspat) ve daha az miktarda kuvars bulunduğu ve mineral tanelerinin soldan sağa doğru bir eğimle yönlenme gösterdikleri belirlenmiştir. Dolayısı ile cevherin metamorfizmaya maruz kaldığı sonucuna varılmıştır (Şekil 4).

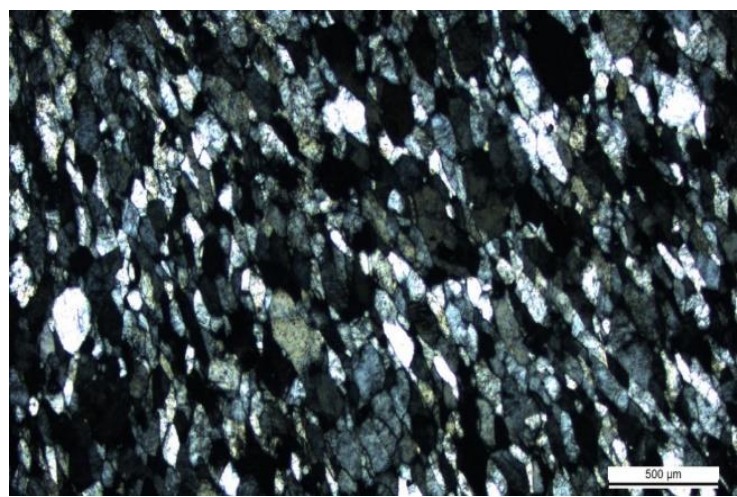

Şekil 4. Feldspat cevherinden hazırlanmış ince kesit mikroskop görüntüsü

Plajioklas tanesi büyütülerek belirgin pijama deseni yapısı ortaya konmuştur (Şekil 5). 


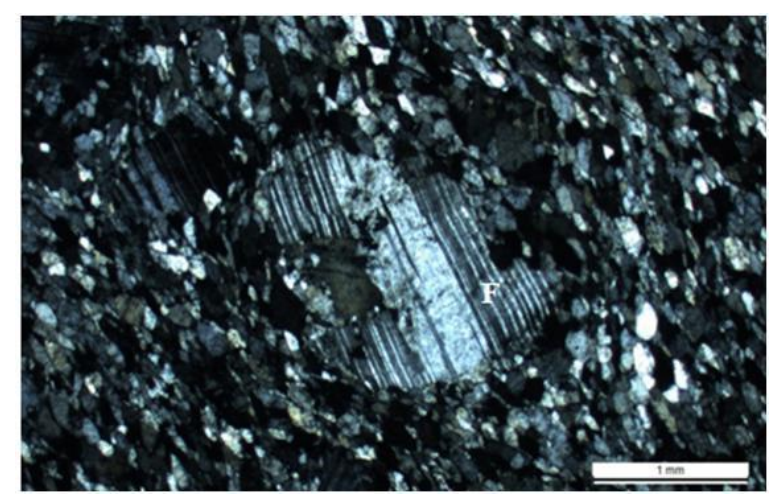

Şekil 5. Pijama desenli plajioklas-feldspat (F) görüntüsü

Şekil 6'da feldspat (F) yanında karakteristik yapısı ile muskovit (M) tanesi görülmektedir.

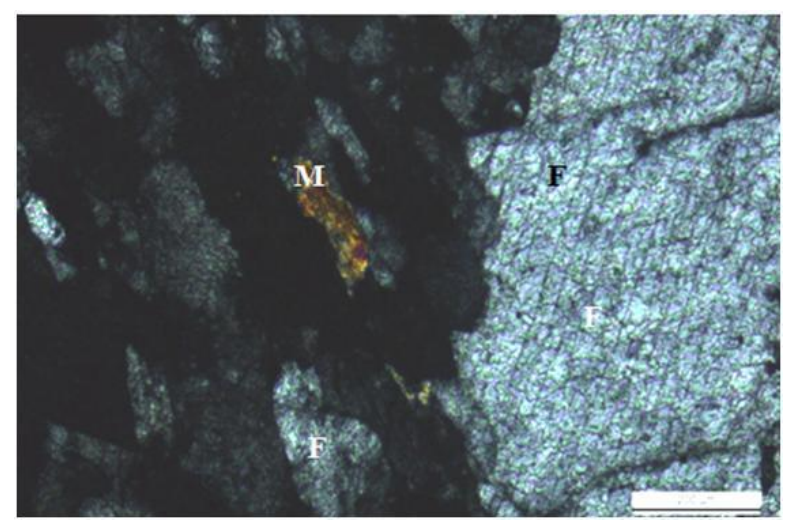

Şekil 6. Plajioklas-feldspat (F) ve muskovit (M) görüntüsü

\subsection{DTA-TGA analizi}

Besleme malı yapısında sıcaklığa bağlı olarak meydana gelen değişimleri belirlemek ve bu sayede XRD ile belirlenen mineralojik bileşimi desteklemek amaciyla numuneye 20$1000{ }^{\circ} \mathrm{C}$ arasındaki sıcaklıklarda DTA-TGA analizi yapılmıştır. Bu analiz sonucunda elde edilen DTA grafiği Şekil 7'de verilmiştir. Grafikte kırmızı ile çizilmiş $450-600^{\circ} \mathrm{C}$ arasındaki yayvan pik bir endotermik reaksiyonu göstermektedir. Bu yayvan pik Ajayil ve Owoeye'nun 2014 yılında yaptıkları çalışma ile örtüşmekte malzemedeki kuvarsın $576^{\circ} \mathrm{C}$ 'deki tipik $\alpha-\beta$ kuvars dönüşümüne işaret etmektedir. Buna göre mineralin tipik pikleri onun $\alpha$ kuvars olduğuna işaret etmektedir [12]. TGA grafiğindeki mavi çizgi ise $\% 0,408$ 'lik çok düşük bir kütle kaybını göstermektedir. TGA eğrisindeki bu $\% 0,408$ 'lik kütle kaybı, kimyasal analiz yöntemi ile belirlenen malzemenin $1000^{\circ} \mathrm{C}$ 'deki $\% 0,55^{\prime}$ 'lik kızdırma kaybı değeri \%KK=0,55 (Tablo 1) ile uyum içerisindedir. 


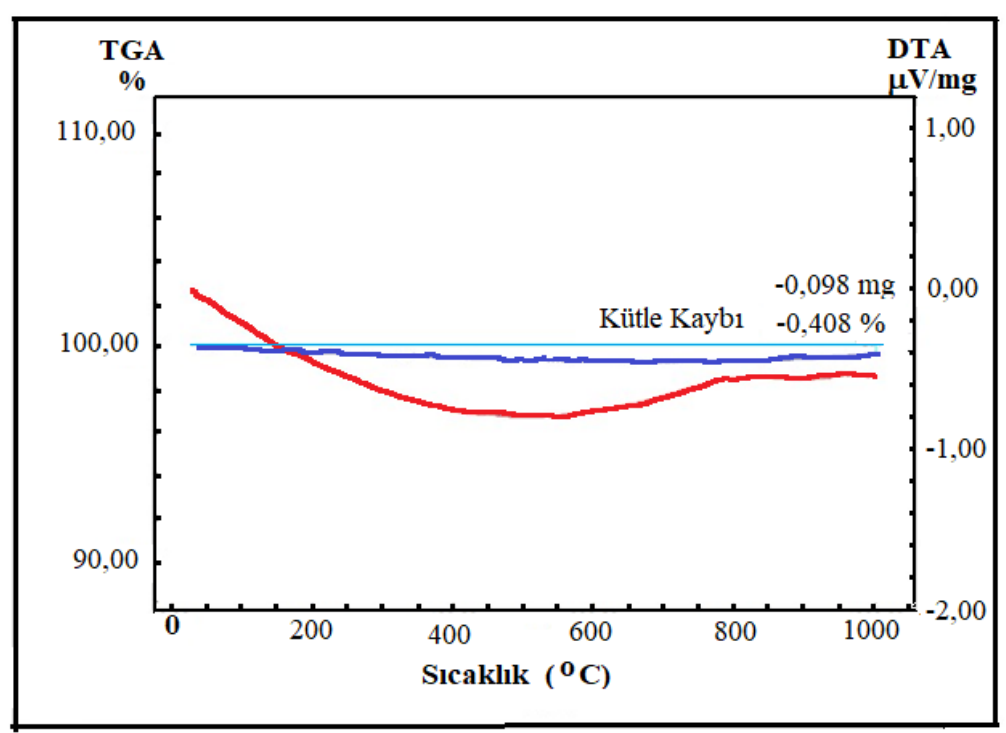

Şekil 7. Besleme malı DTA (kırmızı çizgi)-TGA (lacivert çizgi) grafiği

\subsection{FTIR Analizi}

Feldspat cevheri besleme malının ATR-FTIR grafiği Şekil 8'de görülmektedir. Bu grafik standart Na-feldspat ve K-feldspatın $600-1400 \mathrm{~cm}^{-1}$ arasındaki pikleri (Şekil 9) ile karşılaştırılmış[13] ve standart Na-Feldspatın (Şekil 9-a) FTIR grafiği ile uyumlu olduğu görülmüştür. Bu durumda deneylerde kullanılan numunenin baskın olarak Nafeldspat içerdiği sonucuna varılmıştır. Sodyum feldspat; $\mathrm{Na}_{2} \mathrm{O}, \mathrm{Fe}_{2} \mathrm{O}_{3}$ ve $\mathrm{TiO}_{2}$ içeriğine göre sinıflandırılmaktadır.

Özellikle seramik ve cam sektöründe sinterleme tetikleyicisi olarak kullanılan sodyum feldspat ince tane boyutlarında da boya, plastik ve kauçuk sektörlerinde dolgu malzemesi olarak da kullanılmaktadır. Alümina silikat ailesinden gelen sodyum feldspat seramik bünyelerde, içerdiği $\mathrm{Na}_{2} \mathrm{O}$ ile düşük sıcaklıklarda eriyebilme davranış1 sergilerken, aynı zamanda $\mathrm{Al}_{2} \mathrm{O}_{3}$ ile kimyasal direnç ve sinterleme kararlılı̆̆ sağlamaktadır.

$\mathrm{Bu}$ açıdan numunede FTIR grafiği ile elde edilen piklere göre tanımlanan Na-Feldpat varlığı numunenin hangi alanda kullanılabileceğine karar verme sürecinde son derece önemlidir. 


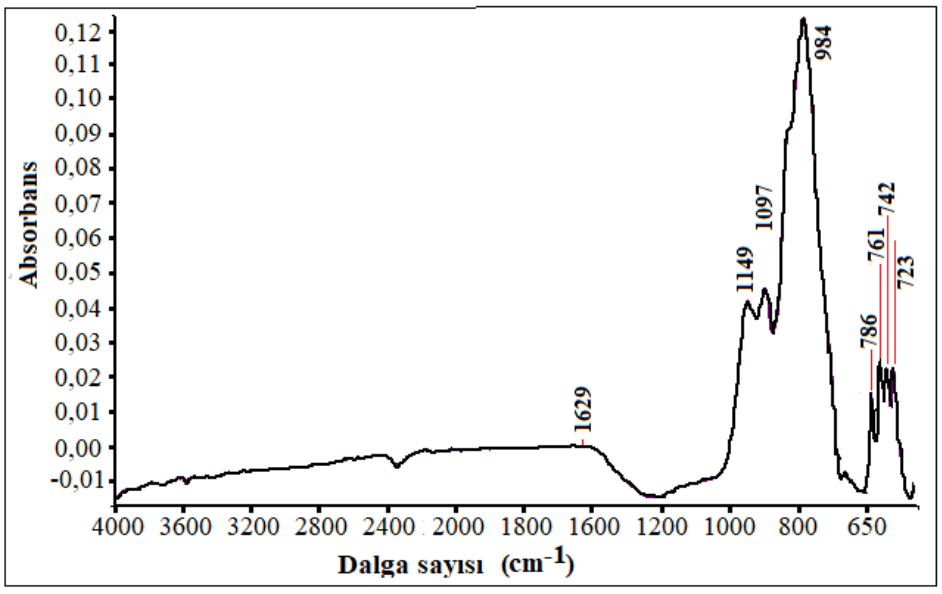

Şekil 8. Besleme malı FTIR-ATR grafiği

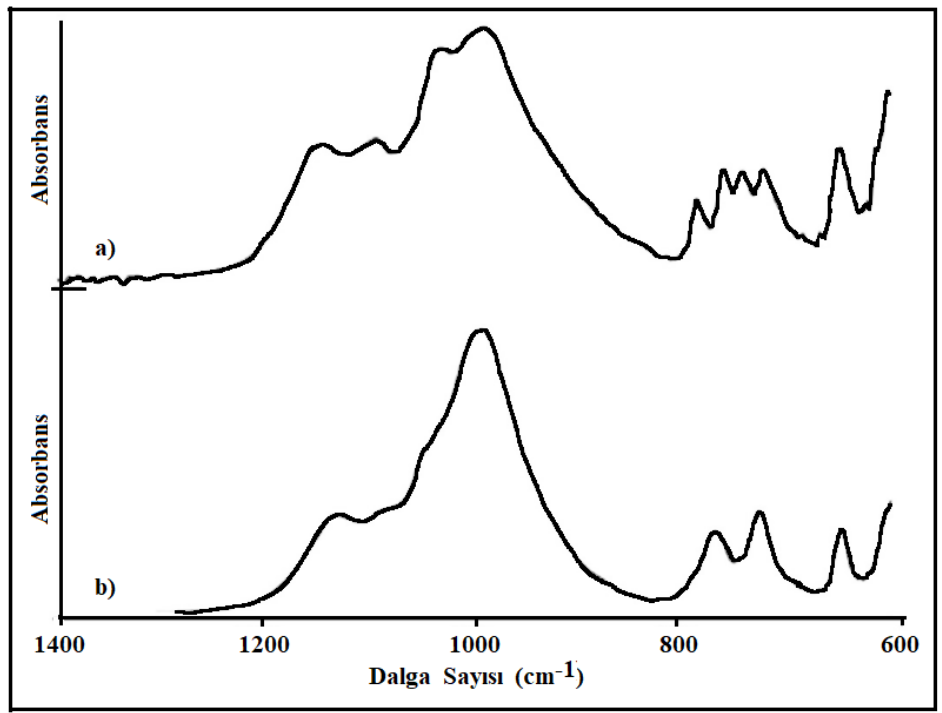

Şekil 9. Standart Na feldspat (a) ve K feldspat (b) ATR-FTIR spektrumları [13]

\subsection{Flotasyon testleri}

Cevherin karakterizasyonu amaciyla yapilan fiziksel ve kimyasal analizler feldspat içerisindeki safsızlıkların hangi minerallere ait olduğunu belirlemekte yetersiz kalmıştır. XRD analizi sonucunda (Şekil 2) sadece ana mineral albit ve ikincil mineral kuvars mineralinin karakteristik pikleri net olarak tanımlanabilmiş ancak binoküler mikroskop (Şekil 3) ve ince kesit incelemelerinde çok az miktarda da olsa görülen rutil, hematit ve muskovit mineralleri (Şekil 4, Şekil 5 ve Şekil 6) tanımlanamamıştır. Mikroskop görüntülerinden elde edilen bulgular cevherin kimyasal analizde belirlenen $\mathrm{Ca}, \mathrm{K}, \mathrm{Fe}$ ve Ti'un (Tablo 1) kaynağı olan mineraller konusunda yol gösterici olmaktadır. Buradan hareketle feldspat cevheri içerisinde eser miktarlarda bulunan minerallerin konsantre edilerek belirlenmesi amacıyla cevhere flotasyon yöntemi uygulanması öngörülmüştür. İçerisinde mika ve ağır mineral ihtiva eden bir feldspat cevherlerinden bu mineralleri uzaklaştırmak amacıyla uygulanan klasik feldspat flotasyonu yöntemi bu çalışmada eser minerallerin konsantrasyonu amacı ile uygulanmıştır. Yapılan işlemin akım şeması Şekil 10'da verilmiştir. Şekil 10'da görülen akım şemasına göre yapılan flotasyon deneyleri oda sıcaklığında $\left(25^{\circ} \mathrm{C}\right), 1 \mathrm{dm}^{3}$ 'lük selülde, $1350 \mathrm{dev} /$ dak karıştırma hızında yapılmış olup, deney şartları ve kullanılan reaktifler Tablo 2'de verilmiştir. 


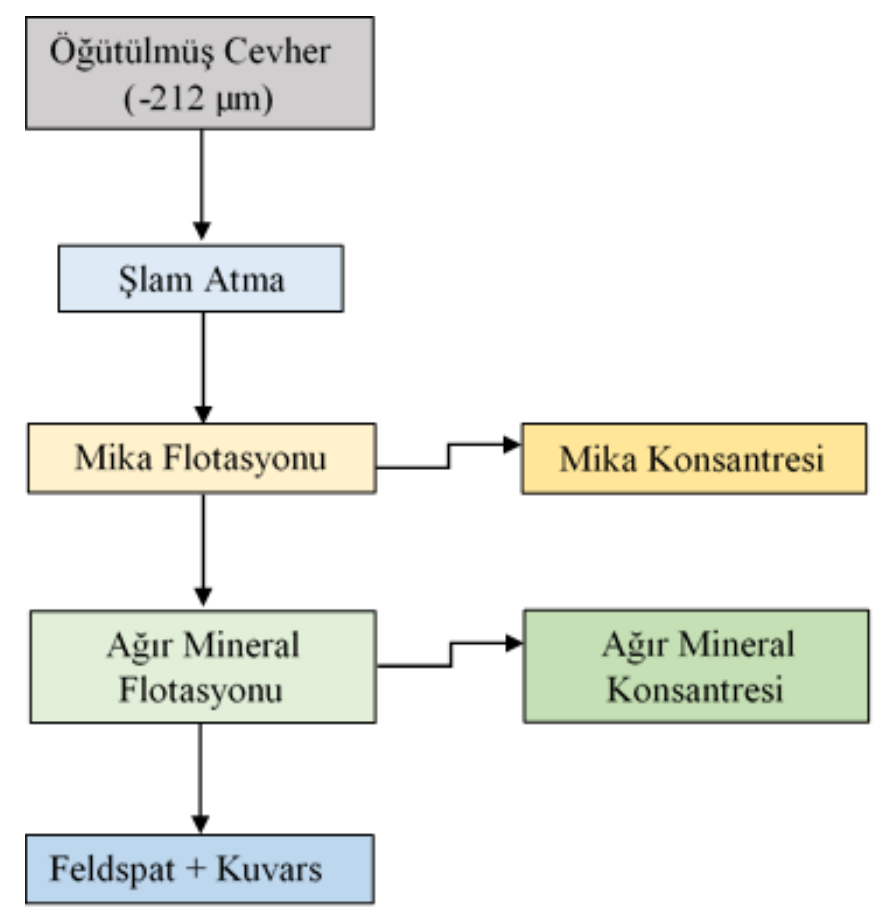

Şekil 10. Çalışmada uygulanan feldspat flotasyonu akım şeması

Burada ilk olarak flotasyonu olumsuz etkileyebilecek ince taneleri uzaklaştırmak amacıyla şlam atma işlemi uygulanmış, ardından iki aşamalı flotasyon işlemine geçilmiştir. Mika flotasyonunda mika mineralleri (muskovit, biyotit vb) konsantre edilirken, ağır mineral flotasyonunda renk verici ve ağır mineraller (demir oksitler, titanyum mineralleri, apatit, vb.) konsantre edilmiştir. Cevherin karakterizasyonu açısından kuvars ve feldspat ayrımı yapmak gereksiz olduğundan feldspat flotasyonu uygulanmamıştır.

Tablo 2. Feldspat flotasyonu deney şartları ve kullanılan reaktifler

\begin{tabular}{|l|l|}
\hline Şlam & \\
\hline Katı/su & $\% 20$ \\
\hline Kondüsyonlama & $7 \mathrm{dk}$. \\
\hline Karıştırma hızı & $\begin{array}{l}1350 \text { dev. / } \\
\text { dk. }\end{array}$ \\
\hline Mika Flotasyonu & \\
\hline pH 3,5 & $\mathrm{H}_{2} \mathrm{SO}_{4}$ \\
\hline Bastırıcı & $\% 10 \mathrm{NaSiO}_{3}$ \\
\hline Toplayıcı & ArmacT \\
\hline Canlandırıcı & $\begin{array}{l}\% 20 \text { Fuel oil } \\
+\% 80 \text { Gaz } \\
\text { yağ1 }\end{array}$ \\
\hline Köpürtücü & $\begin{array}{l}\% 1 \text { Aerofroth } \\
70\end{array}$ \\
\hline Kondüsyonlama & 7 dk. \\
\hline Karıştırma hızı & $\begin{array}{l}1350 \text { dev. / } \\
\text { dk. }\end{array}$ \\
\hline
\end{tabular}


Tablo 2. (Devami).

\begin{tabular}{|l|l|}
\hline $\begin{array}{l}\text { Ă̆ır Mineral } \\
\text { Flotasyonu }\end{array}$ & \\
\hline $\mathrm{pH} 3,5$ & $\mathrm{H}_{2} \mathrm{SO}_{4}$ \\
\hline Bastırıc1 & $\% 10 \mathrm{NaSiO}_{3}$ \\
\hline Toplayıcı & $\begin{array}{l}\% 1 \text { Aero } 825 \\
\% 1 \text { Aero } 869\end{array}$ \\
\hline Köpürtücü & Aerofroth 70 \\
\hline Kondüsyonlama & 7 dk. \\
\hline Karıştırma hızı & $\begin{array}{l}1350 \text { dev. / } \\
\text { dk. }\end{array}$ \\
\hline
\end{tabular}

\subsubsection{Flotasyon ürünlerinin kimyasal analizi}

Reaktif miktarları ve köpük alma süresi değiştirilerek yapılan flotasyon testlerinden en iyi sonuç alınan deney şartlarında karakterizasyon testlerinde kullanılmak üzere ürünler kazanılmıştır. Flotasyon testleri paralel olarak yapılmış elde edilen numunelere ait kimyasal analizler en az üç kez tekrarlanarak alınan ortalama değerler tablo 3 'te verilmiştir.

Tablo 3. Flotasyon ürünlerinin kimyasal analizleri

\begin{tabular}{|c|c|c|c|c|c|}
\hline Ürünler & $\begin{array}{c}\% \\
\mathrm{Fe}_{2} \mathrm{O}_{3}\end{array}$ & $\begin{array}{c}\% \\
\mathrm{~K}_{2} \mathrm{O}\end{array}$ & $\begin{array}{c}\% \\
\mathrm{TiO}_{2}\end{array}$ & $\begin{array}{c}\% \\
\mathrm{Na}_{2} \mathrm{O}\end{array}$ & $\begin{array}{c}\% \\
\mathrm{P}_{2} \mathrm{O}_{5}\end{array}$ \\
\hline Şlam & 0,16 & 0,08 & 0,73 & 9,96 & 0,20 \\
\hline Mika & 0,42 & 0,23 & 0,76 & 10,10 & 0,20 \\
\hline \begin{tabular}{|l} 
A $\mathbf{g}$. \\
Min. \\
\end{tabular} & 0,65 & 0,11 & 3,84 & 10,75 & 3,31 \\
\hline Feld.+Q & 0,04 & 0,12 & 0,60 & 11,09 & 0,08 \\
\hline $\mathbf{B M}$ & 0,12 & 0,19 & 0,79 & 10,49 & 0,27 \\
\hline
\end{tabular}

\subsubsection{Flotasyon ürünlerinin mineralojik analizi}

Flotasyon testlerinden elde edilen ürünlerin XRD grafikleri besleme malı ile karşılaştırmalı olarak Şekil 11'de verilmiştir. Cevher içerisindeki oranları çok düşük olduğundan apatit, rutil ve titanit pikleri besleme malı grafiğinde (Şekil 2) albit pikleri tarafından örtüldüğü için ayırt edilememektedir. Ancak Şekil 11'de görülen Ağır Mineral Konsantresinin XRD grafiğinde albitin ana pikinin sol yanında omuz şeklinde görülen pik ( $\mathrm{R}$ ve $\mathrm{T}$ olarak işaretlenmiş), hem rutil hem de titanitin (sfen) ana pikidir. $\mathrm{Bu}$ durum besleme malında $\% 0,79$ olan $\mathrm{TiO}_{2}$ içeriğinin (Tablo 1) ağır mineral konsantresinde $\% 3,84$ çıkması (Tablo 3) ile de uyum içerisindedir. $\% \mathrm{TiO}_{2}$ oranının ağır mineral konsantresinde artması rutil ve titanitin ağır mineral konsantresinde toplandığını göstermektedir. Aynı şekilde besleme malında \%0,27 olan $\mathrm{P}_{2} \mathrm{O}_{5}$ (Tablo 1) oranının ağır mineral konsantresinde \%3,31 yükselmesi (Tablo 3) apatitin de ağır mineral konsantresinde toplandığına işaret etmektedir. $\mathrm{Bu}$ durum besleme malı XRD grafiğginde albit pikleri altında kalan ve ayırt edilemeyen apatit piklerinin de (A ile işaretli) ağır mineral konsantresinde net olarak görülmesini sağlamıştır. Besleme malı XRD grafiğinde (Şekil 2) görünmeyen ancak mika konsantresinde $M$ ile işaretlenen $\left(2 \theta=9,0^{\circ}\right.$ ve $d=10,01 \AA$ ) muskovitin (mika minerali) karakteristik piki de net olarak görülmektedir. Bu da besleme malında belirgin pik veremeyecek kadar az miktarda bulunan muskovitin, mika flotasyonu ile mika konsantresinde yoğunlaştığını 
göstermektedir (Şekil 11- Mika Konsantresi). Bu durumMika konsantresinin en yüksek $\mathrm{K}_{2} \mathrm{O}$ oranına (\% 0,23) sahip olması ile de uyum içerisindedir (Tablo.3). Bu sonuç aynı zamanda cevherde çok az miktarda bulunan muskovitin, mika flotasyonu ile cevherden uzaklaştırıldığını da göstermektedir (Şekil 11- Feldspat+Kuvars Konsantresi). Yine besleme malında görünmeyen hematit $(\mathrm{H})$ pikinin de ağır mineral konsantresinde belirginleştiği görülmektedir. $\mathrm{Bu}$ da besleme malında \% 0,12 olan $\mathrm{Fe}_{2} \mathrm{O}_{3}$ oranın ağır mineral konsantresinde $\% 0,65$ 'e çıkması ile açıklanmaktadır. Aynı zamanda mika konsantresinde demir oranının artması mika mineralinin demirli olması şeklinde açıklanabilir.

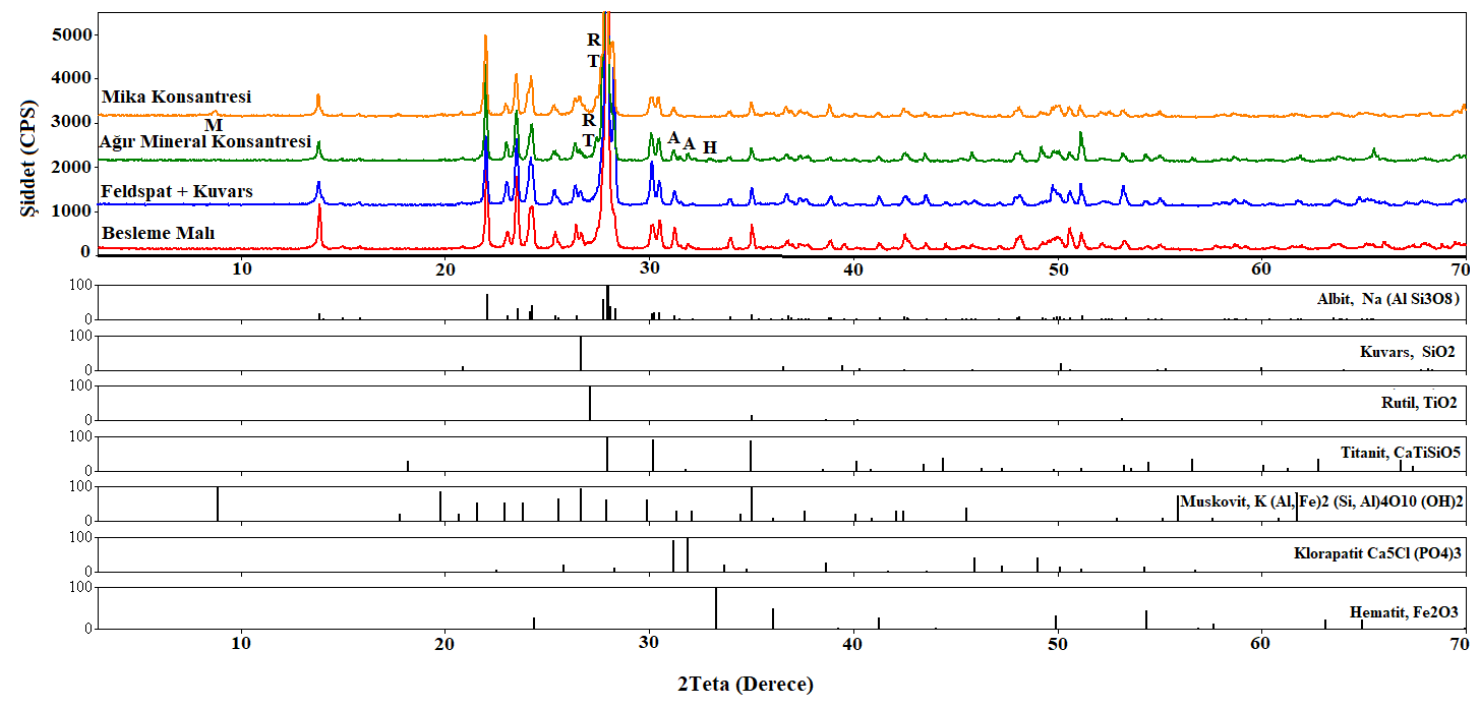

Şekil 11. Besleme malı ile flotasyon ürünlerinin karşılaştırıldığı XRD Grafikleri

\subsubsection{Flotasyon ürünlerinin mikroskobik analizi}

Besleme malı ve flotasyon ürünlerinin mikroskobik incelemesi sonucunda, besleme malında ve mika konsantresinde çok az miktarda bulunan koyu renkli rutil ve titanit mineral taneleri (Şekil $12 \mathrm{a}$ ve b) flotasyondan elde edilen ağır mineral konsantresinde çok daha fazla (Şekil 13a), feldspat+kuvars konsantresinde ise çok az (Şekil 13b) görülmektedir. Buradan rutil, titanit, apatit ve hematit mineralleri ağır mineral konsantresinde toplanırken; ağır minerallerden temizlenmiş bir feldspat+kuvars konsantresinin elde edildiğini söyleyebiliriz (Şekil 13b).

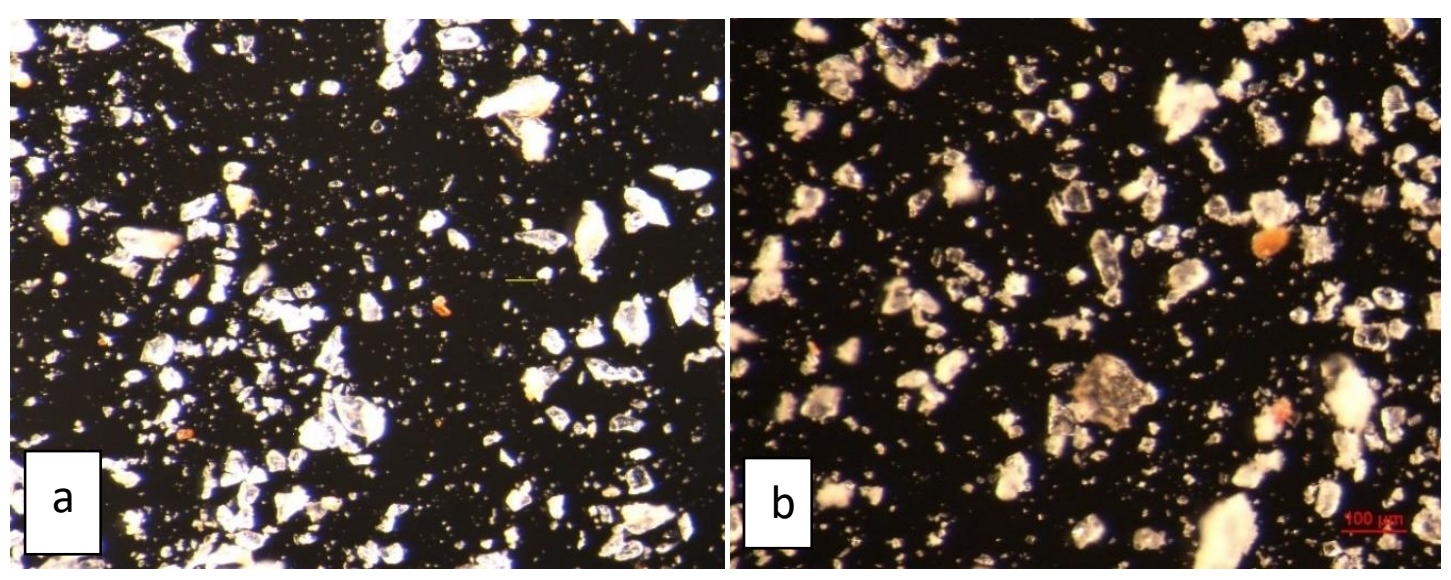

Şekil 12. Besleme malı (a) ve Mika Konsantresi(b) Binoküler Mikroskop Görüntüleri 

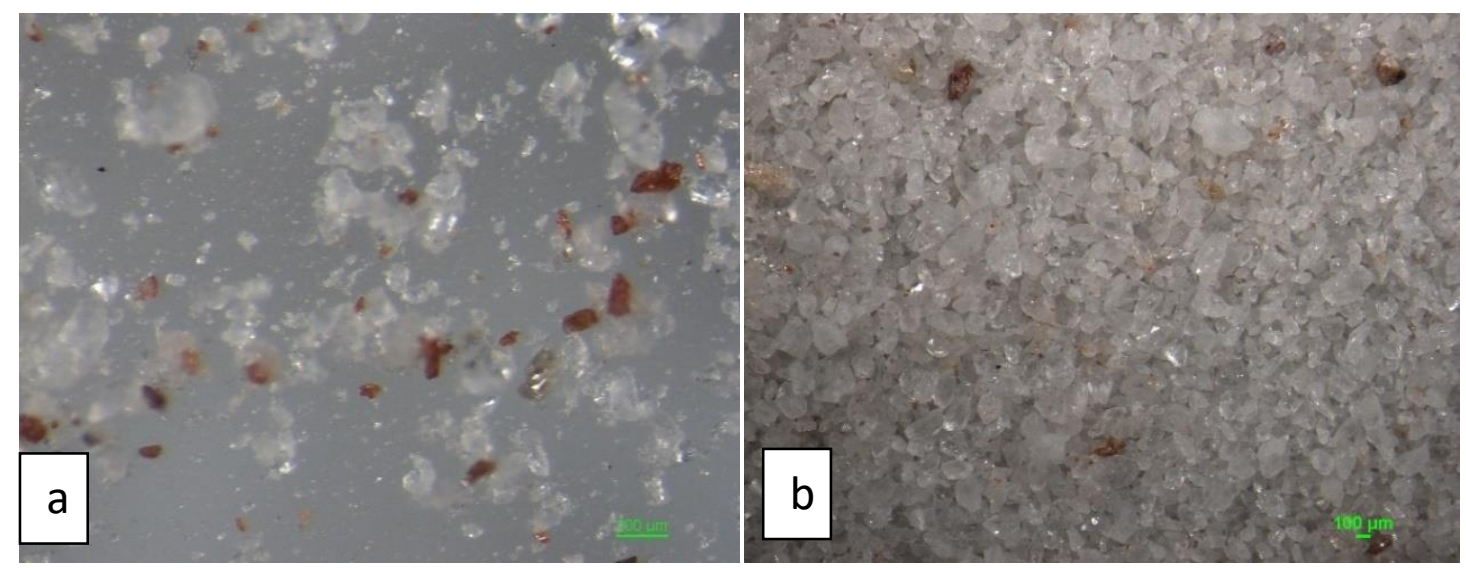

Şekil 13. (a) Ağır Mineral konsantresi ve (b) Feldspat+Kuvars konsantresi binoküler Mikroskop Görüntüleri

\section{Sonuçlar ve tartışma}

$\mathrm{Bu}$ çalışmada Aydın Çine bölgesinden alınan feldspat cevherinin karakterizasyonu farklı analiz yöntemleri kullanılarak yapılmıştır. Cevherin yapılan XRD analizi ile ana mineral albit ve ikincil mineral kuvars kolaylıkla belirlenirken; kimyasal analizle belirlenen demir, titanyum, kalsiyum, magnezyum ve fosfor elementlerinin kaynağ 1 olan minerallerin (muskovit, rutil, sfen, ilmenit, hematit, apatit vb olabilir) cevher içerisindeki oranları çok düşük olduğu için net olarak tespit edilememiştir. Cevher içerisindeki oranlarının düşük olması nedeniyle doğrudan analiz yöntemlerinin belirlemekte yetersiz kalındığı bu durumda eser mineralleri belirleyebilmek amaciyla cevhere flotasyon ile zenginleştirme işlemi uygulanmıştır. Böylece feldspat cevheri flotasyon yöntemi ile zenginleştirilirken artık olarak alınan mika ve ağır mineral konsantreleri cevherde bulunan eser mineralleri belirlemek amaciyla kullanılmıştır. Besleme malına göre daha yüksek oranda bulunan $\mathrm{Fe}_{2} \mathrm{O}_{3}$, mika konsantresinde demirli muskovite, ağır mineral konsantresinde hematite işaret etmektedir. Yine besleme malına göre yüksek oranda bulunan $\mathrm{TiO}_{2}$, ağır mineral konsantresinde rutil ve titanit (sfen) varlığına, $\mathrm{P}_{2} \mathrm{O}_{5}$ ise apatit varlığına işaret etmektedir. Sonuç olarak besleme malında tespit edilemeyen eser mineraller flotasyonla ayrı ayrı zenginleştirilerek elde edilen ürünlerin yapılan kimyasal, mineralojik ve mikroskobik analiz sonuçları birlikte değerlendirilerek tespit edilebilmiştir.

\section{Kaynaklar}

[1] TMMOB Maden Mühendisleri Odas1, Feldspat Raporu, (2010).

[2] http://www.maden.org.tr/resimler/ekler/80ebff16ccaa9b4_ek.pdf

[3] Akar, G., Seyrankaya, A., Güler, E., Akar, A.,Removal of heavy minerals from albite of Muğla-Milas district by froth flotation,8th International Mineral Processing Symposium, Antalya, (2000).

[4] Seyrankaya, A., Akar, A., Güler, E., Akar, G., Aydın-Çine ve Muğla-Milas Feldspatlarının Flotasyonla Zenginleştirilmesi, 2. Endüstriyel Hammaddeler Sempozyumu, Konak, 236-246, (1997).

[5] Akar A. Evaluation of Gördes-Köprübaşı District Feldspar Industrial Raw Material Deposits, Progress in Mineral Processing Technology, Proceedings 
of 5th International Mineral Processing Symposium, p. 243-249, Cappadocia,(1994):

[6] Bayraktar İ., Ersayın S., Gülsoy Ö.Y. Upgrading Titanium Bearing Na-feldspar by Flotation using Sulphonates, Succinamate and Saoaps of Vegetable Oils, Minerals Engineering, Vol. 1, No:12, p. 1363-1374,(1997):

[7] Roger A.K., Van Dyk, D., Feldspars, Industrial Minerals and Rocks, $6^{\text {th }}$ Ed. Donald D. Carr, 473-481. (1994).

[8] Burat, F., Kokkilic, O., Kangal, O., Gurkan, V., Celik, M.S., Quartz-feldspar Separation for the Glass and Ceramics Industries. Miner. Metal. Process., 24, 75-80, (2007).

[9] Burat, F., Feldispat Cevherinin Flotasyon ile Zenginleştirilmesinde Tane Boyutu Değişiminin Etkisi, Çukurova Üniversitesi Mühendislik Mimarlık Fakültesi Dergisi, 32(3), ss. 205-216, (2017).

[10] Karagüzel, C., Yamık, A., Bentli, İ., Beneficiation of Simav-Dağardı Feldspar by Flotation. Proceedings of the 8th International Mineral Processing, (2000).

[11] Çelik, M.S., Can, I., Eren, R.H., Removal of Titanium Impurities from Feldspar Ores by New Flotation Collectors, Minerals Engineering, (1998).

[12] Yılmaz, H., Tanrıverdi, M., Uygun, C., Madencilikte Görüntüleme ve Analiz Cihazlar1.Madencilik, Özel Say1, 51-61, (2018).

[13] Ajayi, B.A., Owoeye, s., Characterization of Okpilla Feldspar Deposit for Glass and Ceramic Production, International Journal of Science and Research (IJSR), (2012).

[14] Bosch-Reig,F., Gimeno-Adelantado, J.V., Bosch-Mossi, F., Domènech,Carbó, A., Quantification of minerals from ATR-FTIR spectra with spectral interferences using the MRC method. Spectrochimica Acta Part A: Molecular and Biomolecular Spectroscopy(2017). 